\title{
Neurosurgical cadaveric and in vivo large animal training models for cranial and spinal approaches and techniques - a systematic review of the current literature
}

\author{
Cezar Octavian Morosanu ${ }^{1}$, Liviu Nicolae ${ }^{1}$, Remus Moldovan², \\ Alexandru Stefan Farcasanu ${ }^{3}$, Gabriela Adriana Filip ${ }^{2}$, Ioan Stefan Florian ${ }^{4}$ \\ ${ }^{1}$ Department of Neurosurgery, Southmead Hospital, North Bristol NHS Trust, Bristol, UK \\ ${ }^{2}$ Department of Physiology, Iuliu Hatieganu University of Medicine and Pharmacy, Romania \\ ${ }^{3}$ Faculty of Physics, Babes-Bolyai University, Cluj-Napoca, Romania \\ ${ }^{4}$ Department of Neurosurgery, Iuliu Hatieganu University of Medicine and Pharmacy, Romania
}

\section{ABSTRACT}

Introduction. Due to its high complexity, neurosurgery consists of a demanding learning curve that requires intense training and a deep knowledge of neuroanatomy. Microsurgical skill development can be achieved through various models of simulation, but as human cadaveric models are not always accessible, cadaveric animal models can provide a reliable environment in which to enhance the acquisition of surgical dexterity. The aim of this review was to analyse the current role of animal brains in laboratory training and to assess their correspondence to the procedures performed in humans.

Material and methods. A Pubmed literature search was performed to identify all the articles concerning training cranial and spinal techniques on large animal heads. The search terms were 'training model', and 'neurosurgery'in association with 'animal', 'sheep', 'cow', and 'swine.' The exclusion criteria were articles that were on human brains, experimental fundamental research, or on virtual simulators.

Results. The search retrieved 119 articles, of which 25 were relevant to the purpose of this review. Owing to their similar neuroanatomy, bovine, porcine and ovine models prove to be reliable structures in simulating neurosurgical procedures. On bovine skulls, an interhemispheric transcalosal and retrosigmoid approach along with different approaches to the Circle of Willis can be recreated. Ovine model procedures have varied from lumbar discectomies on sheep spines to craniosynostosis surgery, whereas in ex vivo swine models, cadaveric dissections of lateral sulcus, median and posterior fossa have been achieved.

Conclusions. Laboratory training models enhance surgical advancements by familiarising trainee surgeons with certain neuroanatomical structures and promoting greater surgical dexterity. The accessibility of animal brains allows trainee surgeons to exercise techniques outside the operating theatre, thus optimising outcomes in human surgical procedures.

Key words: cadaveric, training, neurosurgical model, large animals

(Neurol Neurochir Pol 2019; 53 (1): 8-17)

\section{Introduction}

Neurosurgery, through its various approaches and techniques, requires a refinement of surgical skills that can only be achieved through continuous practice. Consequently, the necessity for training structures is essential in the understanding of the anatomical background on which surgical steps are constituted. Cadaveric human heads have the disadvantage of

Address for correspondence: Cezar Octavian Morosanu, Deparment of Neurosurgery Southmead Hospital, Bristol,

e-mail: cezaroctavian.morosanu@yahoo.com 
being inaccessible to every institution due to ethical considerations. However, animal models are characterised by a high feasibility in cost-efficient reproducibility. Consistent practice pays large dividends in the operating theatre.

Education in medical training in the past decade has undergone various metamorphoses, reaching a point where virtual reality can be accessed to train surgical gestures. But the value of biologic material is irreplaceable since it is the only one which provides genuine hands-on training on a texture that is similar to human tissue. Ruminant and porcine models have been successfully used to recreate operations of high fidelity in the neurosurgical field. In a comparative study, Sidhu et al. [1] revealed that training on biological tissues was more efficient for gaining fine motor skills than on synthetic devices. Furthermore, certain studies have acknowledged the deficit in educating surgical skills in certain areas. For instance, Boszczyk et al. looked into the competence of European neurosurgical trainees in spine surgery, and drew attention to confidence issues in the management of spinal trauma and various approaches. In any domain requiring dexterity, it is vital for novices to practice basic techniques in order to train their striatum/cerebellar based functions [2].

The rationale behind our review was to answer the question as to whether cadaveric animal models play a role in the cerebral and spinal surgical learning curve. In order to understand the current knowledge about training models, the aim was to gather all the information available in the literature to establish the current status of neurosurgical simulation in cadaveric animal brains. The hypothesis was that animal models have a high impact on trainee activity and development and are an adequate replacement for human cadavers. This would give them a potential role in the curricula of trainees.

\section{Material and methods}

Our review was structured with the PRIMA (Preferred Reporting Items for Systematic Reviews and Meta-Analyses) methodology [3] and comprises an analysis of the past 15 years on articles referring to training techniques on cadaveric animal cephalic extremities or spines. The search terms were a combination of 'training model' and 'neurosurgery' with 'animal' OR 'sheep' OR 'cow' OR 'swine'.

\section{Eligibility criteria}

Only manuscripts that were articles in English were taken into consideration. Inclusion criteria were the description of cranial and spinal procedures that were simulated on ex vivo and in vivo material that had been obtained from veterinary-controlled facilities. All studies that evaluated live surgery in fundamental research, biomechanical experiments on nonliving tissues, case reports, veterinary studies or any other article that described procedures with any purpose other than surgical training were excluded. Furthermore, anatomical research was not relevant to the purpose of this review.

\section{Literature search}

Comprehensive literature searches were performed on Pubmed and Google Scholar, using a timeframe from 2003 to 2018 and the results were imported to EndNote X5.

\section{Study selection}

The criteria for study selection focused on the set of techniques. Abstracts and in extenso papers were verified for information regarding any method of training with the primary target of improving surgical procedures.

There were certain exclusion criteria taken into consideration such as the publication of abstracts only, letters, comments, reviews, or meta-analyses; animal studies; languages other than English; duplicate studies; veterinary purposes; aspects related to comparative anatomy, artificial material or virtual reality or human cadaveric training models. Furthermore, any other training model in a non-neurosurgical field such as otology or rhinology was excluded. After removing excluded abstracts, full articles were obtained and studies were screened once again more thoroughly, using the same exclusion criteria (Fig. 1).

\section{Data collection process and data items}

The analysis was undertaken by two reviewers independently (COM and LN) and any discrepancy was solved through a consensus. Data regarding the year of the study, the name of the first author, the type of animal model used, and the procedure used for training were collected.

The literature search revealed 119 articles of interest, of which 25 were deemed suitable for inclusion (Tab. 1).

\section{Results}

The search retrieved 119 articles, 25 of which were in accordance with our criteria. There appears to be an increased interest in ovine heads generating accurate models, both for spinal and cranial procedures. Bovine heads, both injected with silicone and fresh from butchery, carry the advantage of having large anatomical elements that have greater visibility under the microscope. The only in vivo model was a porcine head used to assess competency in bone drilling, dissecting the brain and preserving cerebral vessels under microscopic magnification.

\section{Ovine models}

Due to their particular anatomy and size, sheep (Ovis aries) have been used as experimental large animal models in a multitude of specialities in biomedical research varying from orthopedics for biomaterial implants [4] to cardiovascular surgery [5]. In terms of neuroanatomical similarities, sheep exhibits many resemblances to the human regarding electroencephalographic elements [6], neuroradiological features [7] (Fig. 2, Fig. 3), functional imaging [8], neurovascular structure [9] as well as sleep homeostasis [10], making it an 


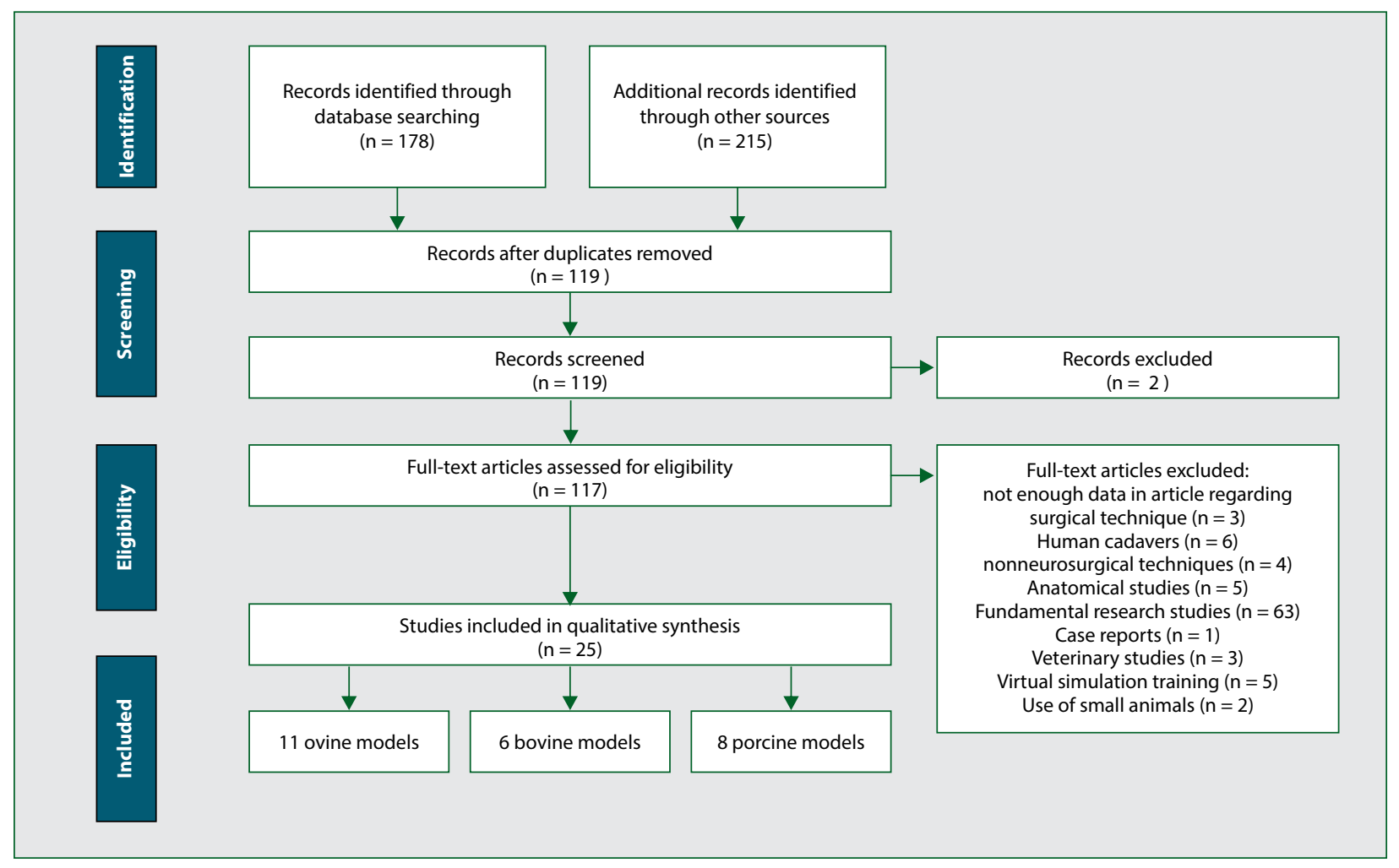

Figure 1. PRISMA 2009 Flow Diagram. From: Moher D, Liberati A, Tetzlaff J, Altman DG, The PRISMA Group (2009). Preferred Reporting Items for Systematic Reviews and Meta-Analyses: The PRISMA Statement

excellent specimen in translational neuroscience. Cadaveric sheep brains (Fig. 4) provide very accurate teaching material for mammalian cerebral anatomy and are highly accessible to everyone to learn the homologous neural structures through careful dissection [11]. Several neurosurgical techniques have been attempted to enhance knowledge and familiarity with certain cranial approaches. Hamamcioglu et al. (2008) described a four-step laboratory dissection under the operating microscope of cranial nerves in the posterior fossa. Positioned in the lateral side, a $3 \times 3 \mathrm{~cm}$ craniectomy was performed in the ovine skull in the right paramedian suboccipital bone. Access to the cerebellomedulary cistern and cerebellopontine angle was done through the retraction of the right cerebellar lobe medially. This permits the dissection of the right cranial nerves and nerves VII to IV. This step was followed by the opening of the right lateral cerebellomedullary cistern with an arachnoid knife and a pair of microscissors and dissection of the lower cranial nerves IX to XII using appropriate instruments such as bipolar forceps and suction tube. Identification of the right cerebellopontine angle and cranial nerves V, VII and VIII. The last step has the potential of training in the field of trigeminal decompression identifying the necessary elements and placing a small piece of plastic sheet between the trigeminal nerve and the vessel [12].

Another ovine cranial approach is the one focusing on orbital surgery simulation proposed by Altunrende et al.
[13] that could prove an effective manner of training both for neurosurgeons as well as for ophthalmologists. The superior orbitotomy approach and the frontal intracranial approach have been described and divided into different surgical steps. The orbitotomy starts with a subperiostal periorbital dissection aiming to remove the superior orbital margin and roof, which allows access to the retroocular structures, with a rongeur. The second procedure permits the visualisation of the optic nerve and the optic canal through a $3 \times 3 \mathrm{~cm}$ craniectomy in the frontal bone. After opening the dura in a semicircular manner, the dissection of the sylvian fissure, carotid and basal cisterns and the optic nerve in the anterior skull base can be performed. The optic canal was unroofed using a rongeur, and the optic nerve was exposed. Although the topographic anatomy and the size of the ovine orbit are different in certain aspects, the model can be easily used to aid training in orbital surgery.

In the field of paediatric neurosurgery, training in the area of craniosynostosis can be very useful in familiarizing the surgical trainee in the operative steps, the thickness of the calvarial and facial bone being similar to that found in paediatric patients. The craniofacial procedure was designed in three steps and can be used to understand the surgical options in cases of anterior plagiocephaly, trigonocephaly, and brachycephaly. After performing the subperiosteal and subperiorbital dissection, the bifrontal craniotomy is commenced. The 
Table 1. Literature focused on specified animal anatomical regions

\begin{tabular}{|c|c|c|c|c|}
\hline Year & Author & Cadaveric model & Organ & Procedure \\
\hline 2003 & Borucki et al. & Pig & Brain & Endoscopy in the cerebellopontine angle \\
\hline 2005 & Kalayci et al. & Sheep & Spine & Lumbar discectomy \\
\hline 2006 & Hicdonmez et al. & Cow & Brain & Approach to the Circle of Willis \\
\hline 2006 & Hicdonmez et al. & Sheep & Brain & Craniosynostosis surgery \\
\hline 2006 & Hamamcioglu et al. & Cow & Brain & Interhemispheric-transcallosal approach \\
\hline 2008 & Hamamcioglu et al. & Sheep & Brain & Posterior fossa and cranial nerves dissection \\
\hline 2009 & Walker et al. & Deer & Spine/Skull & Minimally invasive spinal surgery/Calvarium drilling \\
\hline 2011 & Olabe et al. & Pig & Brain & Aneurysm surgery \\
\hline 2011 & Anderson et al. & Calf & Spine & Dural repair \\
\hline 2012 & Suslu et al. & Sheep & Spine & Pedicle screw fixation \\
\hline 2012 & Suslu et al. & Sheep & Spine & Transforaminal epidural injection \\
\hline 2013 & Suslu et al. & Cow & Brain & Retrosigmoid approach \\
\hline 2014 & Suslu et al. & Sheep & Spine & Lumbar microdiscectomy \\
\hline 2014 & Aurich et al. & Pig & Brain & Various cortical dissections \\
\hline 2014 & Altunrende et al. & Sheep & Brain & Orbital and optic nerve dissection \\
\hline 2014 & Silva et al. & Pig & Brain & Skull base endoscopy and microsurgery \\
\hline 2014 & Vavruska & Sheep & Brain & Intraoperative brain ultrasound \\
\hline 2015 & Kamp et al. & Sheep & Brain & Tumour dissection \\
\hline 2015 & Smith et al. & Sheep & Spine & Perfused spine dissections \\
\hline 2015 & Regelsberger et al. & Pig & Brain & In vivo sulcal, transcortical dissection \\
\hline 2016 & Gragnaniello et al. & Sheep & Spine & Spinal mass \\
\hline 2017 & Cuellar et al. & Pig & Spine & Endoscopic interlaminar discectomy \\
\hline 2018 & Gokyar et al. & Cow & Brain & $\begin{array}{l}\text { Bilateral sylvian cisterns, interhemispheric fissure, } \\
\text { and hemispheric sulcus dissection }\end{array}$ \\
\hline 2018 & Hanrahan et al. & Pig & Brain & Dura mater suturing \\
\hline 2018 & Hanrahan et al. & Pig & Brain & Intracranial bolt insertion \\
\hline
\end{tabular}

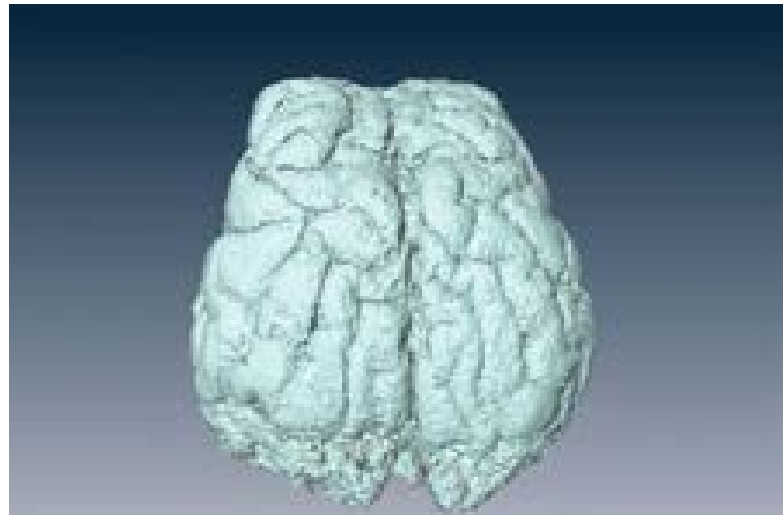

Figure 2. MRI 3D reconstruction of a sheep brain - superior view

supraorbital bar is separated from the dura and osteotomies aid in its separation from the orbital roof and nasal midline. The last step implies the reconstruction of the forehead. This is done with appropriate fixation from plates and screws and involves advancing the supraorbital bar and positioning it in

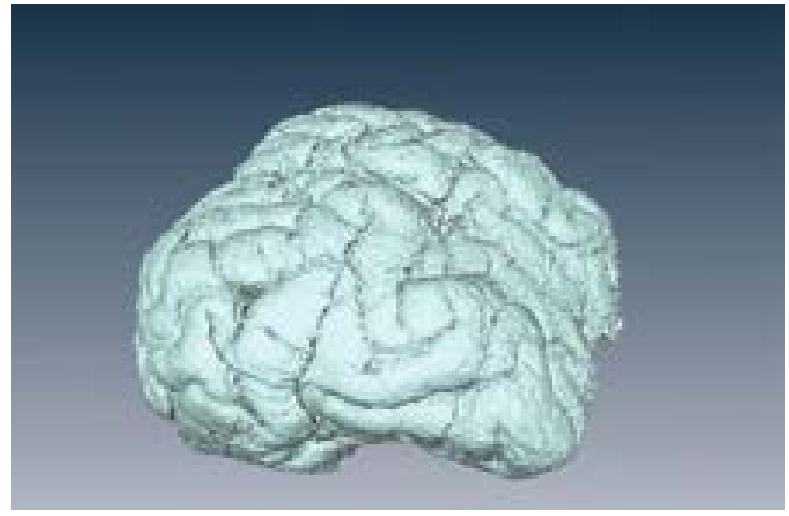

Figure 3. MRI 3D reconstruction of a sheep brain - lateral view

the proper anatomy [14]. Compared to virtual simulators [15], the model is cheaper, easy to manouevre, and does not require any complex technological instrumentation. It should be noted that despite the fact that human cadaveric models are much more suitable for training, there has not yet been described 


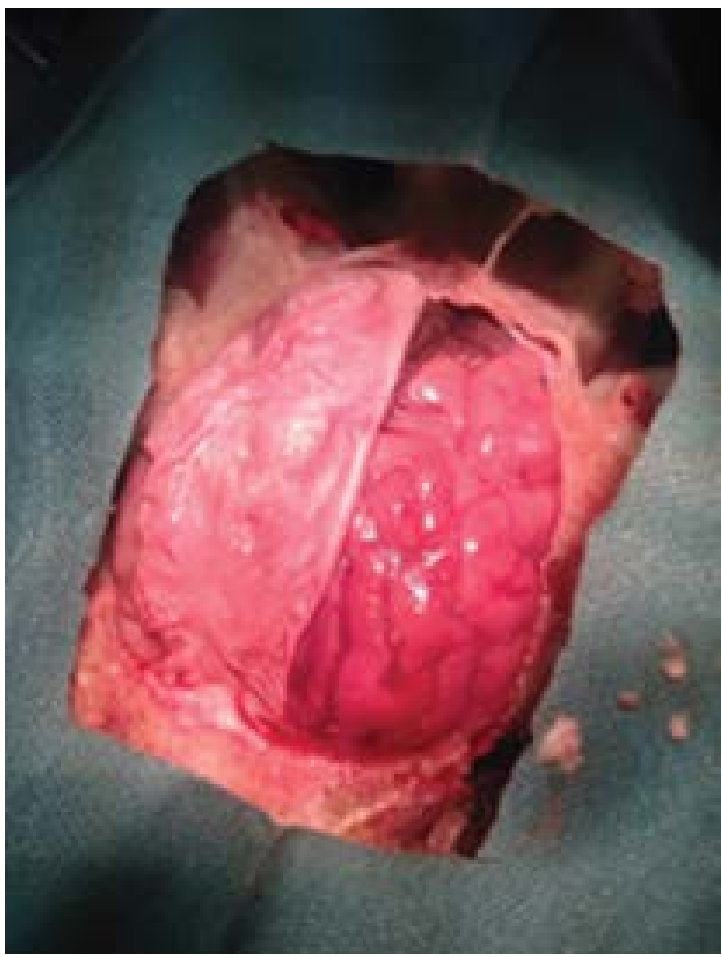

Figure 4. Dissection of cadaveric sheep head

a model in the literature that can achieve the development of surgical skills on a paediatric skull.

There have also been attempts to determine a model suitable for neuro-oncological training, to enhance surgical dexterity in handling cerebral tissue and distinguishing it from abnormal anatomy. Thus, Kamp et al. (2015) recreated cerebral masses in cadaveric sheep brains using an agar-agar and ink solution that was injected subcortically through an 18 gauge needle. With proper instrumentation such as a surgical microscope, an ultrasound device and a CUSA (ultrasonic tissue ablation system), a corticotomy and gyrus dissection were performed in order to reach the targeted tumour. Although it is an in vitro design, it can assist us greatly in our understanding of the preservation of eloquent areas in oncological surgery. The model was assessed by two senior neurosurgeons, five phycians and ten medical students, receiving good and very good overall feedback [16]. A collection of procedures that could prove to be highly useful in the laboratory was also designed by Sabel M. [17]. These include basic principles of planning a procedure, craniotomy skills using a coconut, familiarisation with the microscopic field where sutures can be enhanced on chicken wings, subpial resection and tumour resection on a synthetic model. To aid certain approaches to such a pathology, intraoperative ultrasound is frequently used to assess the position of the tumour. Training in this regard has been explored by Vavruska et al. [18], who evaluated the sheep brain with a transducer and identified similar structures to the human brain.
In terms of spinal surgery, lumbar discectomy was experimented by Kalayci et al. [19] and a model of lumbar microdiscectomy was proposed by Suslu et al. (2014) on ovine spines under fluoroscopic guidance. Sheep lumbar intervertebral discs have proven to have similar levels of water content, collagen percentage and fibre orientation to those in human, collagen percentage and fibre orientation angles to their human counterparts [20]. In Suslu's study, exposure of the lumbar spine was carried out through an incision in the median fascia and dissection of the paravertebral muscles from the lamina in a subperiosteal plane. Using the operating microscope, the microdiscectomy was carried out through a partial hemilaminectomy, preserving the epidural fat and the ligamentum flavum. The ligament was dissected away from the dura and eventually removed laterally to visualise the nerve root and the pedicle. The posterior longitudinal ligament was afterwards incised after retracting the thecal sac with the nerve roots and the disc was removed [21].

In addition, the same author performed two other spinal procedures on sheep spines, namely a percutaneous lumbar transforaminal epidural injection [22], and a laboratory pedicular screw fixation [23]. The epidural injection is a procedure through which a steroid is injected into the intervertebral foramen, and it is used for lumbar disc pathology with intense pain. It requires a good understanding of the anatomy of the region, and a cadaveric model can provide the resources to identify them. Suslu et al. (2012) described a four-step technique in which a 22 gauge needle is inserted percutaneously in the ovine spine through the neural foramen with the help of anteroposterior and oblique fluoroscopic images. After checking that the needle is in the proper position, lateral to the 6 oclock site under the lumbar pedicle, $2 \mathrm{~mL}$ of non-ionic contrast material is injected to assess the contrast spread along the epidural space.

The other method innovated by Suslu et al. (2011) was the laboratory pedicular screw fixation. This technique first requires the identification of the main pedicle landmarks. Under $\mathrm{C}$-arm fluoroscopy, a Kerrison rongeur is used to decorticate the bone followed by the manual insertion of a handled awl in the vertebral body through the centre of the pedicle. After taking appropriate precautions, a $4.5 \mathrm{~mm}$ diameter and $35 \mathrm{~mm}$ length screw is positioned in the tunnel formed in the vertebral structures. This relatively straightforward method can be easily learned, and, in improving the experience of spinal surgery trainees, will ultimately lead to fewer neurologic injuries due to screw misplacements and better surgical outcomes.

There has also been a perfused spine model described by Smith et al. (2015) in a rural setting. The main vessels were ligated, catheterised and connected to a pump and the subdural space was filled with SALF water, thus simulating the qualities of a living tissue. The training techniques utilized here consist of watertight dural suturing and leak repair [24]. In terms of more complex spine surgery, the mass effect related pathology, such as the one seen in tumours, has been documented by 
Gragnaniello et al. [25] who in 2016 described a fluoroscopic injection with Stratathane resin ST-504 into an ovine spine, thus creating a similar spinal lesion.

\section{Bovine models}

The anatomy of the central nervous system of domestic cattle has been less studied in comparison with other species [26]. Ruminant brains in general have a similar organisation, with differences involving the architecture of the insula, of the diencephalon, the arrangement of the gyri in the cortex as well as the position of the visual and olfactory systems [27]. The neuromorphology of bovines is very similar to that of sheep, and the imagistic particularities can be used in translational research due to their structure [28]. Given their weight and structure, their brains can be successfully used in neurodegenerative disease investigations [29]. The angioanatomy has certain particularities. The vascular structure supply of the arterial circle of the brain, for example, in the Bos genus, is done mainly by the maxillary artery through a particular anatomical element identified as the paired rostral epidural rete mirabile. The unpaired caudal epidural rete mirabile contributes to the circle of the brain from vertebral and occipital arteries, thus making it a characteristic trait in these animals [30].

One of the procedures that can be performed on bovine heads is the interhemispheric-transcallosal approach to the lateral ventricle, which simulates in a very accurate manner the surgical steps performed in humans. This consists of four steps, each corresponding to a part of the human intervention allowing the visualisation of the callosomarginal and pericallosal arteries, as well as the cingulate gyrus. The first step is a paramedian craniectomy and the retraction of the frontoparietal lobe. This develops an access point to enhance the dissection of the callosomarginal arteries and the corpus callosum. Opening the corpus callosum and eventually entering the ventricle can reveal further neuroanatomical elements, such as the choroid plexus or the foramen of Monro, and also vascular structures such as the septal and thalamostriate veins [31].

Another bovine microneurosurgical model that has been successfully assessed by Hicdonmez et al. (2006) is a procedure that aimed to coordinate surgical steps in order to perform an adapted pterional approach towards the circle of Willis. Hicdonmez, too, utilized a four step approach, in four stages as well, starting with access to the carotid and chiasmatic cisterns by retraction of the right frontal lobe. The optic nerve, the rostral/anterior cerebral artery and the medial cerebral artery can also be viewed in this point. The nomenclature used for the anterior cerebral artery in bovine vascular anatomy is 'rostral cerebral artery'; the term 'posterior cerebral artery' is replaced by 'caudal cerebral artery' and the frontal lobe is known as the 'rostral lobe'. Other elements that can be observed after opening the chiasmatic cistern are the optic chiasm, the anterior communicating artery complex, the internal ethmoidal artery and the corresponding A1 of the anterior cerebral artery in the human brain. The dissection of the internal carotid artery is carried out in order to identify the trajectory of various vessels and located medially to it is the pituitary stalk. The authors simulated a clipping of the exit segment of the caudal communicating artery from the internal carotid artery, and this proved highly significant in mimicking the conditions in which aneurysm surgery is performed [32].

The retrosigmoid approach was also achieved on a silicone injected cow brain by Suslu et al. (2013) who accessed the cerebellopontine angle (CPA) and exemplified the anatomical elements that can be encountered in such a procedure. The experimental design allowed an enhanced understanding of neurostructures through the red and blue silicone injected in the major vessels. Visualisation of the right cerebellar lobe was made possible through a right paramedian suboccipital craniectomy. The lobe was retracted medially and the cistern was opened through gentle dissection. The right CPA and cranial nerves VII and VIII were identified. This was followed by the opening of the lateral cerebellomedullary cistern which revealed the IX, X, XI and XII cranial nerves from the brainstem [33].

In a more recent study, cerebral dissection on cow brains was also achieved by Gokyar et al. [34] who dissected bilaterally the sylvian cisterns, as well as the interhemispheric fissure and hemispheric sulcus.

Bovine models have been found to be of use in spinal procedures, as well. A calf spinehas has proven useful in recreating dural repairs [35], while a deer model has been tested in a nontransparent Plexiglass frame for minimally invasive spinal surgery and assessed by surgical trainees who noticed encouraging results [36].

\section{Porcine models}

Swine models have been a useful tool in general digestive laparoscopic surgery [37], urology [38], maxillofacial surgery [39], paediatric surgery [40] and oculoplastics [41] for a long time. There have also been comparative studies that aimed to evaluate the effectiveness of both human cadaveric and pig models. These identified higher relevance in swines for tissue handling and the ability to dissect anatomical planes [42]. Their use in neurosurgery has been increasing because there are numerous similarities to the human cerebrum [43]. Magnetic resonance imaging in pigs has revealed impressive equivalences $[44,45]$, permitting various introspections in the field of deep brain stimulation [46] as well as in neurovascular research [47].

Various cranial procedures have been investigated both in vivo and ex vivo. In the nonliving head, the interhemispheric fissure can be dissected, allowing the inspection of the cingulate gyrus, callosomarginal and pericallosal arteries. This also accesses the corpus callosum through which the lateral ventricle and the foramen of Monro could be visualised in the context of a transcallosal approach. Middle fossa dissection enabled the identification of the middle meningeal arteries and the V2, V3 branches of the trigeminal nerve. The optic nerve 
and the carotid artery were observed through an approach in the lateral sulcus. The cerebellopontine angle was evaluated through instrumentations to the cerebellum, and the brainstem was carefully dissected to expose the fourth ventricle and cranial nerves [48].

Furthermore, Silva et al. [49] achieved microsurgical and endoscopic procedures on a nonliving swine head, managing to perform a transnasal approach and a middle and posterior fossa dissection, thus demonstrating the similarities between human and pig anatomical areas.

In pig models, suturing the dura mater was a skill that was trained under the microscope in a more recent study performed by Hanrahan et al. [50]. In this swine model, the authors investigated the effect that anxiety has on hand tremor, assessing dexterity through the Johnson O'Connor Tweezer Test and anxiety through the Westside Test Anxiety Scale. Their conclusion was that tremor does not interfere with the ability to suture the dura and that confidence plays a major role in our task performance.

Another technique that was investigated by the same author on swine models was the insertion of an intracranial pressure monitor in an ex vivo pig head. This was done with the aim of developing an interest among medical students in neurosurgery. A Codman hand drill, an intracranial pressure monitor and a transducer were the instruments used on the cadaveric specimen, and the training was accompanied by lectures related to the pathophysiology of raised pressure in the cranium [51].

Although not cadaveric models, it is relevant to discuss in vivo models that have been successful in developing surgical skills for the sole purpose of exemplifying the usefulness of animals in training young neurosurgeons. Compared to other models, pigs seem to have unique qualities that render them excellent in in vivo practice. Regelsberger et al. (2015) used living pigs to perform neurosurgical procedures, to establish microsurgical principles in order to work under the surgical microscope, to manoeuvre neurosurgical instruments in a living brain, and to control bleeding during tissue handling. Certain aspects were trained such as the proper use of surgical equipment in a craniotomy, the basics of cerebral sulcal, transcortical, parenchymal and subpial tissue dissection, the management of sinusoidal, subarachnoid or intracerebral bleeding through various techniques, and dural repair. Due to its realistic laboratory set up, the course was widely appreciated by the participants, and the management of complications that occurred on a living brain was an important key learning point for neurosurgical physicians, an element that has an immense advantage over cadaveric models [52].

Aneurysm surgery was also experimented in swine by inducing this vascular pathology on 1-2 months old domestic pigs. A bifurcation aneurysm was created by two arteries and one vein, and then sulfuric acid was applied to contribute to the fragility of the vessel. The experiment created 22 aneurysms in different locations simulating situations such as thrombosis or rupture. Clipping techniques were trained as well as vascular reconstruction in emergency circumstances [53].

Another living animal model was used by Borucki et al. (2003) in performing a neuroendoscopic procedure in pigs. The aim was to expose the cerebellopontine angle through the retrosigmoid approach, training surgical steps that are valuable in acoustic neuroma surgery [54].

Experimental spinal surgery on pigs was only attempted by Cuellar et al. [55], who successfully managed to operate an endoscopic interlaminar discectomy.

\section{Discussion}

The role of laboratory cadaveric and non-cadaveric animal dissection is quintessential in developing surgical skills to be able to practice microneurosurgical interventions on patients. The purpose of this review was to elaborate on collection of all the known methods of animal model training and assess their effectiveness in harnessing important abilities in the management of surgical patients. Apart from temporal bone dissection, all current animal neurosurgical procedures were reviewed. Techniques such as temporal bone drilling, although valuable to the neurosurgeon, are mostly used in ENT training courses and vary from training on chicken eggs [56] to 3D printed models [57]. Swine models are frequent examples in this kind of technique [58], and sheep temporal bones have also been used [59], but there is a multitude of experimental designs that have proven their utility. A very insightful review on this topic was published by Bergin et al. [60] which identified 11 animal models that can be used for middle ear surgery, as well as Wiet et al. [61] who researched otologic training models.

Human cadavers are the most accurate training models. Working on cadavers has the advantages of enhancing the visualisation of the anatomy that the neurosurgeon will have to face during any surgical intervention. The limitations are clearly the costs of keeping, and the difficulties in obtaining, human cadavers, as well as the ethical quandaries that are particular to the legislation of each country. Despite all of these obstacles, the educational benefit is indisputable. There have also been attempts to perfuse cadavers to bring about a more realistic approach in human brains such as endoscopic skull base procedures [62] or aneurysm surgery [63].

Live animals compared to nonliving animals have clear advantages. However, in familiarizing the neurosurgical trainee to the anatomical background, cadaveric models prove equally as important. Identifying anatomical elements of the ovine, bovine or porcine brain and spine helps better understanding of human anatomy. Maneoeuvring different components with microinstruments familiarises the trainee with surgical conditions, and allows the development of their dexterity in working with fragile neurostructures.

Surgical workshops on live animals must have local approvals and meet adequate requirements both from an ethical 
and veterinary point of view. Local laws and animal research codes of practice have to be followed. There needs to be a clear justification for the use of animals and a careful assessment if the education goals can be met by other means (e.g. cadaveric, simulation workshops). The participants require an appropriate postgraduate level of training to maximize their benefit. During these workshops, adequate veterinary supervision is mandatory to ensure monitoring and maintaining anaesthesia to minimise any animal suffering.

In the context of ethics, there are some limitations on the use of bovine anatomical elements in training in countries such as India, or the use of porcine models in the Middle East due to cultural issues, meaning that there is a need to consider other animal options.

The disadvantage of cadaveric brains is that there is no indicator of haemorrhage, whereas managing haemostasis is an important aspect of any operation. In this context, pigs are the only animals cited in the literature to have had neurosurgical training procedures done in in vivo conditions.

Another risk that is related to sheep and cow central nervous tissue is that of contracting ovine or bovine spongiform encephalopathy. However, although this issue is present, it is highly unlikely that such a pathology will be encountered if the head specimens are sourced from a unit that is under veterinary supervision.

Training in nonliving brains has an important impact on surgical experience. A survey done on 100 neurosurgery programmes in the USA evaluated the prevalence, particularities and extent of laboratory dissection in different departments across the country. The courses varied from one to six sessions annually, with an active participation of trainee surgeons from years 2 to 6, covering topics such as cranial, spinal and neuroendoscopy approaches to cadavers or virtual reality simulators. These courses are regarded as very important, and the results of the questionnaire revealed that $89.2 \%$ of doctors would support a national dissection curriculum and manual [64].

So, rather than being occasional courses carried out by national or international societies, animal cadaver courses could be implemented as important hands-on workshops on a regular basis in the training of surgeons.

\section{Conclusions}

Animal models provide highly valuable experience for those training to be neurosurgeons. Although there are various obstacles to overcome such as anatomical differences, enhancing surgical skills on animal brains can improve performance on the operating table. Ovine, bovine as well as porcine cerebrums and spines are usually easily obtained. This subsequently makes them ideal material for mimicking surgical procedures. Furthermore, frequent workshops and operative courses on these models should be popularised during surgical training to help trainees develop a better comprehension of neuroanatomy and better neurosurgical outcomes.

\section{Declaration of interest}

There are no conflicts of interest. We do not have a financial relationship to the work, neither have we received any other form of financial support, nor any government or company grants or research support.

\section{Acknowledgements}

The authors wish to thank the significant contribution of Mr. Dan Priscu and Dr. Adelina Priscu in proofreading the article.

\section{References}

1. Sidhu RS, Park J, Brydges R, et al. Laboratory-based vascular anastomosis training: a randomized controlled trial evaluating the effects of bench model fidelity and level of training on skill acquisition. J Vasc Surg. 2007; 45(2): 343-349, doi: 10.1016/j.jvs.2006.09.040, indexed in Pubmed: 17264015.

2. Haase J, Boisen E. Neurosurgical training: more hours needed or a new learning culture? Surg Neurol. 2009; 72(1): 89-95; discussion 95, doi: 10.1016/j.surneu.2009.02.005, indexed in Pubmed: 19559933.

3. Moher D, Liberati A, Tetzlaff J, et al. Preferred Reporting Items for Systematic Reviews and Meta-Analyses: The PRISMA Statement. PLoS Medicine. 2009; 6(7): e1000097, doi: 10.1371/journal. pmed.1000097.

4. Sartoretto SC, Uzeda MJ, Miguel FB, et al. SHEEP AS AN EXPERIMENTAL MODEL FOR BIOMATERIAL IMPLANT EVALUATION. Acta Ortop Bras. 2016; 24(5): 262-266, doi: 10.1590/1413-785220162405161949, indexed in Pubmed: 28149193.

5. DiVincenti L, Westcott R, Lee C. Sheep (Ovis aries) as a model for cardiovascular surgery and management before, during, and after cardiopulmonary bypass. J Am Assoc Lab Anim Sci. 2014; 53(5): 439-448.

6. Opdam HI, Federico P, Jackson GD, et al. A sheep model for the study of focal epilepsy with concurrent intracranial EEG and functional MRI. Epilepsia. 2002; 43(8): 779-787, indexed in Pubmed: 12180994.

7. Boltze J, Förschler A, Nitzsche B, et al. Permanent middle cerebral artery occlusion in sheep: a novel large animal model of focal cerebral ischemia. J Cereb Blood Flow Metab. 2008; 28(12): 1951-1964, doi: 10.1038/jcbfm.2008.89, indexed in Pubmed: 18698332.

8. Lee W, Lee SD, Park MY, et al. Functional and diffusion tensor magnetic resonance imaging of the sheep brain. BMC Vet Res. 2015; 11: 262, doi: 10.1186/s12917-015-0581-8, indexed in Pubmed: 26467856.

9. Hoffmann A, Stoffel MH, Nitzsche B, et al. The ovine cerebral venous system: comparative anatomy, visualization, and implications for translational research. PLoS One. 2014; 9(4): e92990, doi: 10.1371/ journal.pone.0092990, indexed in Pubmed: 24736654.

10. Perentos N, Martins AQ, Cumming RJM, et al. An EEG Investigation of Sleep Homeostasis in Healthy and CLN5 Batten Disease Affected Sheep. J Neurosci. 2016; 36(31): 8238-8249, doi: 10.1523/JNEUROSCl.4295-15.2016, indexed in Pubmed: 27488642.

11. Grisham W. Resources for teaching Mammalian neuroanatomy using sheep brains: a review. J Undergrad Neurosci Educ. 2006; 5(1): R1R6, indexed in Pubmed: 23495310. 
12. Hamamcioglu MK, Hicdonmez T, Tiryaki M, et al. A laboratory training model in fresh cadaveric sheep brain for microneurosurgical dissection of cranial nerves in posterior fossa. Br J Neurosurg. 2008; 22(6): 769-771, doi: 10.1080/02688690802477573, indexed in Pubmed: 19085361.

13. Altunrende ME, Hamamcioglu MK, Hıcdonmez T, et al. Microsurgical training model for residents to approach to the orbit and the optic nerve in fresh cadaveric sheep cranium. J Neurosci Rural Pract. 2014; 5(2): 151-154, doi: 10.4103/0976-3147.131660, indexed in Pubmed: 24966554.

14. Hicdonmez T, Parsak T, Cobanoglu S. Simulation of surgery for craniosynostosis: a training model in a fresh cadaveric sheep cranium. Technical note. J Neurosurg. 2006; 105(2 Suppl): 150-152, doi: 10.3171/ped.2006.105.2.150, indexed in Pubmed: 16922078.

15. Coelho G, Warf B, Lyra M, et al. Anatomical pediatric model for craniosynostosis surgical training. Childs Nerv Syst. 2014; 30(12): 2009-2014, doi: 10.1007/s00381-014-2537-x, indexed in Pubmed: 25183390.

16. Kamp MA, Knipps J, Steiger HJ, et al. Training for brain tumour resection: a realistic model with easy accessibility. Acta Neurochir (Wien). 2015; 157(11): 1975-81; discussion 1981, doi: 10.1007/s00701015-2590-6, indexed in Pubmed: 26407857.

17. Sabel M. Getting Ready for Brain Tumor Surgery Paperback. Thieme 2016: Thieme.

18. Vavruska J, Buhl R, Petridis AK, et al. Evaluation of an intraoperative ultrasound training model based on a cadaveric sheep brain. Surg Neurol Int. 2014; 5: 46, doi: 10.4103/2152-7806.130314, indexed in Pubmed: 24818053.

19. Kalayci M, Cagavi F, Gül S, et al. A training model for lumbar discectomy. J Clin Neurosci. 2005; 12(6): 673-675, doi: 10.1016/j. jocn.2004.12.004, indexed in Pubmed: 16054364.

20. Reid JE, Meakin JR, Robins SP, et al. Sheep lumbar intervertebral discs as models for human discs. Clin Biomech (Bristol, Avon). 2002; 17(4): 312-314, indexed in Pubmed: 12034126.

21. Suslu HT, Tatarli N, Karaaslan A, et al. A practical laboratory study simulating the lumbar microdiscectomy: training model in fresh cadaveric sheep spine. J Neurol Surg A Cent Eur Neurosurg. 2014; 75(3): 167-169, doi: 10.1055/s-0032-1330114, indexed in Pubmed: 23397126.

22. Suslu H. A practical laboratory study simulating the percutaneous lumbar transforaminal epidural injection: training model in fresh cadaveric sheep spine. Turk Neurosurg. 2012; 22(6): 701-705, doi: 10.5137/1019-5149.JTN.5899-12.2, indexed in Pubmed: 23208900.

23. Turan Suslu H, Tatarli N, Hicdonmez T, et al. A laboratory training model using fresh sheep spines for pedicular screw fixation. $\mathrm{Br} J$ Neurosurg. 2012; 26(2): 252-254, doi: 10.3109/02688697.2011.619598, indexed in Pubmed: 22087885.

24. Smith A, Gagliardi F, Pelzer NR, et al. Rural neurosurgical and spinal laboratory setup. J Spine Surg. 2015; 1(1): 57-64, doi: 10.3978/j. issn.2414-469X.2015.09.02, indexed in Pubmed: 27683680.

25. Gragnaniello C, Abou-Hamden A, Mortini P, et al. Complex Spine Pathology Simulator: An Innovative Tool for Advanced Spine Surgery Training. J Neurol Surg A Cent Eur Neurosurg. 2016; 77(6): 515-522, doi: 10.1055/s-0036-1583940, indexed in Pubmed: 27367357.

26. Zimmerl U. II sistema nervoso. In: Bossi V, Caradonna GB, Spampani G. ed. Trattato di Anatomia veterinaria, Vol 3. Vallardi, Milano 1909: 4-294.

27. Schmidt MJ, Langen N, Klumpp S, et al. A study of the comparative anatomy of the brain of domestic ruminants using magnetic resonance imaging. Vet J. 2012; 191(1): 85-93, doi: 10.1016/j. tvjl.2010.12.026, indexed in Pubmed: 21277239.

28. Schmidt MJ, Pilatus U, Wigger A, et al. Neuroanatomy of the calf brain as revealed by high-resolution magnetic resonance imaging. J Morphol. 2009; 270(6): 745-758, doi: 10.1002/jmor.10717, indexed in Pubmed: 19123244.

29. Ballarin C, Povinelli M, Granato A, et al. The Brain of the Domestic Bos taurus: Weight, Encephalization and Cerebellar Quotients, and Comparison with Other Domestic and Wild Cetartiodactyla. PLoS One. 2016; 11(4): e0154580, doi: 10.1371/journal.pone.0154580, indexed in Pubmed: 27128674.

30. Zdun M, Frąckowiak H, Kiełtyka-Kurc A, et al. The arteries of brain base in species of Bovini tribe. Anat Rec (Hoboken). 2013; 296(11): 1677-1682, doi: 10.1002/ar.22784, indexed in Pubmed: 24106047.

31. Hicdonmez T, Hamamcioglu MK, Parsak T, et al. A laboratory training model for interhemispheric-transcallosal approach to the lateral ventricle. Neurosurg Rev. 2006; 29(2): 159-162, doi: 10.1007/s10143005-0014-4, indexed in Pubmed: 16374648.

32. Hicdonmez T, Hamamcioglu MK, Tiryaki M, et al. Microneurosurgical training model in fresh cadaveric cow brain: a laboratory study simulating the approach to the circle of Willis. Surg Neurol. 2006; 66(1): 100-4; discussion 104, doi: 10.1016/j.surneu.2005.09.027, indexed in Pubmed: 16793460.

33. Turan Suslu H, Ceylan D, Tatarlı N, et al. Laboratory training in the retrosigmoid approach using cadaveric silicone injected cow brain. Br J Neurosurg. 2013; 27(6): 812-814, doi: 10.3109/02688697.2013.772095, indexed in Pubmed: 23458576.

34. Gökyar A, Cokluk C. Using of Fresh Cadaveric Cow Brain in the Microsurgical Training Model for Sulcal-Cisternal and Fissural Dissection. J Neurosci Rural Pract. 2018; 9(1): 26-29, doi: 10.4103/jnrp. jnrp_390_17, indexed in Pubmed: 29456341.

35. Anderson PA. Surgical simulation: Dural repair. http://www.cns.org/ publications/cnsq/pdf/CNSQ_11summer.pdf (2014 Sep 08).

36. Walker JB, Perkins E, Harkey HL. A novel simulation model for minimally invasive spine surgery. Neurosurgery. 2009; 65(6 Suppl): 188-195, doi: 10.1227/01.NEU.0000341534.82210.1B.

37. La Torre M, Caruso C. The animal model in advanced laparoscopy resident training. Surg Laparosc Endosc Percutan Tech. 2013; 23(3): 271-275, doi: 10.1097/SLE.0b013e31828b895b, indexed in Pubmed: 23751991.

38. He B, Musk GC, Mou L. Laparoscopic surgery for orthotopic kidney transplant in the pig model. J Surg Res. 2013; 184(2): 1096-1101, doi: 10.1016/j.jss.2013.03.015.

39. Mardas N, Dereka X, Donos N, et al. Experimental model for bone regeneration in oral and cranio-maxillo-facial surgery. J Invest Surg. 2014; 27(1): 32-49, doi: 10.3109/08941939.2013.817628, indexed in Pubmed: 23957784.

40. Esposito C, Escolino M, Draghici I, et al. Training Models in Pediatric Minimally Invasive Surgery: Rabbit Model Versus Porcine Model: A Comparative Study. J Laparoendosc Adv Surg Tech A. 2016; 26(1): 79-84, doi: 10.1089/lap.2015.0229, indexed in Pubmed: 26619331.

41. Zou C, Wang JQ, Guo X, et al. Pig eyelid as a teaching model for severe ptosis repair. Ophthalmic Plast Reconstr Surg. 2012; 28(6): $472-$ 474, doi: 10.1097/IOP.0b013e31826a5146, indexed in Pubmed: 23138217.

42. Stefanidis D, Yonce TC, Green JM, et al. Cadavers versus pigs: which are better for procedural training of surgery residents outside the OR? 
Surgery. 2013; 154(1): 34-37, doi: 10.1016/j.surg.2013.05.001, indexed in Pubmed: 23809483.

43. Sauleau $P$, Lapouble E, Val-Laillet $D$, et al. The pig model in brain imaging and neurosurgery. Animal. 2009; 3(8): 1138-1151, doi: 10.1017/S1751731109004649, indexed in Pubmed: 22444844.

44. Conrad MS, Dilger RN, Johnson RW. Brain growth of the domestic pig (Sus scrofa) from 2 to 24 weeks of age: a longitudinal MRI study. Dev Neurosci. 2012; 34(4): 291-298, doi: 10.1159/000339311, indexed in Pubmed: 22777003.

45. Conrad MS, Sutton BP, Dilger RN, et al. An in vivo three-dimensional magnetic resonance imaging-based averaged brain collection of the neonatal piglet (Sus scrofa). PLoS One. 2014; 9(9): e107650, doi: 10.1371/journal.pone.0107650, indexed in Pubmed: 25254955.

46. Gorny KR, Presti MF, Goerss SJ, et al. Measurements of RF heating during 3.0-T MRI of a pig implanted with deep brain stimulator. Magn Reson Imaging. 2013; 31(5): 783-788, doi: 10.1016/j. mri.2012.11.005, indexed in Pubmed: 23228310.

47. Habib CA, Utriainen D, Peduzzi-Nelson J, et al. MR imaging of the yucatan pig head and neck vasculature. J Magn Reson Imaging. 2013; 38(3): 641-649, doi: 10.1002/jmri.24003, indexed in Pubmed: 23348984.

48. Aurich LA, Silva Junior LF, Monteiro FM, et al. Microsurgical training model with nonliving swine head. Alternative for neurosurgical education. Acta Cir Bras. 2014; 29(6): 405-409, indexed in Pubmed: 24919051.

49. Silva L, Aurich L, Monteiro F, et al. Microsurgical and Endoscopic Training Model with Nonliving Swine Head: New Alternative for Skull Base Education. Journal of Neurological Surgery Part B: Skull Base. 2014; 75(S 01), doi: 10.1055/s-0034-1370596.

50. Hanrahan J, Sideris M, Pasha T, et al. Hands train the brain-what is the role of hand tremor and anxiety in undergraduate microsurgical skills? Acta Neurochir (Wien). 2018; 160(9): 1673-1679, doi: 10.1007/ s00701-018-3609-6, indexed in Pubmed: 29968093.

51. Hanrahan J, Sideris M, Tsitsopoulos P, et al. Increasing motivation and engagement in neurosurgery for medical students through practical simulation-based learning. Annals of Medicine and Surgery. 2018; 34 : 75-79, doi: 10.1016/j.amsu.2018.08.002.

52. Regelsberger J, Eicker S, Siasios I, et al. In vivo porcine training model for cranial neurosurgery. Neurosurg Rev. 2015; 38(1): 157-63; discussion 163, doi: 10.1007/s10143-014-0572-4, indexed in Pubmed: 25240530.
53. Olabe J, Olabe J, Roda J. Microsurgical cerebral aneurysm training porcine model. Neurol India. 2011; 59(1): 78-81, doi: 10.4103/00283886.76872, indexed in Pubmed: 21339668.

54. Borucki Ł, Szyfter W. [Evaluation of an animal model in endoscopic surgery of the cerebello-pontine angle]. Otolaryngol Pol. 2003; 57(3): 385-388, indexed in Pubmed: 14524182.

55. Cuéllar G, Rugeles J. ENDOSCOPIC INTERLAMINAR DISCECTOMY. USE OF SWINE CADAVERS AS A TRAINING MODEL. Coluna/Columna. 2017; 16(2): 116-120, doi: 10.1590/s1808-185120171602147361.

56. Meléndez García JM, Araujo Da Costa AS, Rivera Schmitz T, et al. Temporal bone dissection practice using a chicken egg. Otol Neurotol. 2014; 35(6): 941-943, doi: 10.1097/MA0.0000000000000390, indexed in Pubmed: 24841916.

57. Mowry SE, Jammal H, Myer C, et al. A Novel Temporal Bone Simulation Model Using 3D Printing Techniques. Otol Neurotol. 2015; 36(9): 1562-1565, doi: 10.1097/MA0.0000000000000848, indexed in Pubmed: 26375979.

58. Garcia L, Andrade J, Testa J. Anatomical study of the pigs temporal bone by microdissection. Acta Cirurgica Brasileira. 2014; 29(suppl 3): 77-80, doi: 10.1590/s0102-86502014001700014.

59. Gurr A, Stark T, Probst G, et al. [The temporal bone of lamb and pig as an alternative in ENT-education]. Laryngorhinootologie. 2010; 89(1): 17-24, doi: 10.1055/s-0029-1224158, indexed in Pubmed: 19691010.

60. Bergin M. Systematic review of animal models of middle ear surgery. World Journal of Otorhinolaryngology. 2013; 3(3): 71, doi: 10.5319/ wjo.v3.i3.71.

61. Wiet GJ, Sørensen MS, Andersen SA. Otologic Skills Training. Otolaryngol Clin North Am. 2017; 50(5): 933-945, doi: 10.1016/j. otc.2017.05.005, indexed in Pubmed: 28822580.

62. Pham M, Kale A, Marquez Y, et al. A Perfusion-based Human Cadaveric Model for Management of Carotid Artery Injury during Endoscopic Endonasal Skull Base Surgery. J Neurol Surg B Skull Base. 2014; 75(5): 309_ 313, doi: 10.1055/s-0034-1372470, indexed in Pubmed: 25301092.

63. Aboud E, Aboud G, Al-Mefty 0, et al. "Live cadavers" for training in the management of intraoperative aneurysmal rupture. Journal of Neurosurgery. 2015; 123(5): 1339-1346, doi: 10.3171/2014.12. jns141551.

64. Kshettry VR, Mullin JP, Schlenk R, et al. The role of laboratory dissection training in neurosurgical residency: results of a national survey. World Neurosurg. 2014; 82(5): 554-559, doi: 10.1016/j. wneu.2014.05.028, indexed in Pubmed: 24875190. 